Revista Brasileira de Agricultura Irrigada v.8, n. 1, p. 26 - 37, 2013

ISSN 1982-7679 (On-line)

Fortaleza, CE, INOVAGRI - http://www.inovagri.org.br

DOI: $10.7127 /$ rbai.v8n100204

Protocolo 204.13 - 02/12/2013 Aprovado em 26/02/2014

\title{
CANA-DE-AÇÚCAR: PARÂMETROS TECNOLÓGICOS EM FUNÇÃO DE DIFERENTES LÂMINAS DE IRRIGAÇÃO E ADUBAÇÃO DE COBERTURA
}

\author{
Cira Belém Gonçalves Correia ${ }^{1}$, Hamilton Medeiros de Azevedo ${ }^{2}$, José Dantas Neto ${ }^{2}$, Clayton \\ Moura de Carvalho ${ }^{3}$, Leonaria Luna Silva ${ }^{4}$ e Simone de Oliveira Feitosa ${ }^{4}$
}

\begin{abstract}
RESUMO
A importância da cana-de-açúcar, no cenário atual agrícola brasileiro, pode ser atribuída à sua elevada capacidade de adaptação aos diversos ambientes edafoclimáticos. No entanto a determinação dos parâmetros tecnológicos da cana-de-açúcar, especialmente o teor de sólidos solúveis, teor de sacarose, pureza do caldo, fibra e percentagem bruta de açúcar, é fundamental para comercialização da cana. Sendo assim o objetivo deste trabalho foi observar a variação dos parâmetros tecnológicos da cana-de-açúcar sob quatro lâminas de irrigação e dois níveis de adubação de cobertura. Utilizou-se o esquema fatorial 2 x 4 e o delineamento inteiramente casualizado, com 3 repetições. Após análise estatística dos dados, constatou-se que a interação dos dois fatores irrigação e adubação influenciaram significativamente o teor de sólidos solúveis da quinta folha de cana-de-açúcar variedade SP 791011. O teor de sacarose e a pureza do caldo aumentaram seus valores de acordo com a lâmina d'água. A fibra e a pureza do caldo encontrados neste experimento com o quinto corte da cana-de-açúcar foram superiores aos valores encontrados por outros autores que trabalharam, com a mesma variedade e no mesmo local do experimento, com cortes de cana anteriores.
\end{abstract}

Palavras-chave: qualidade, pivô central, Saccharum officinarum L.

\section{CANE SUGAR: TECHNOLOGICAL PARAMETERS FOR EACH DIFFERENT BLADES OF IRRIGATION AND FERTILIZATION OF COVERAGE}

\begin{abstract}
The importance of cane sugar in the current Brazilian agricultural scenario can be attributed to its high adaptability to different environments edaphoclimatic. However the determination of technological parameters of cane sugar, especially the soluble solids, sucrose, purity of the broth, and crude fiber percentage of sugar is essential for commercialization of sugarcane . Therefore the aim of this study was to observe the variation of technological parameters of cane sugar under four irrigation and two levels of manuring. We used a 2 x 4 factorial and completely randomized design with 3 replications. After statistical analysis, it was found that

\footnotetext{
${ }^{1}$ Mestre em Engenharia Agrícola, Prof. da FATEC Cariri, e-mail: cirabg@ hotmail.com

2 Doutor em Engenharia Agrícola, Prof. da UFCG, e-mail: hamilton@deag.ufcg.edu.br, zedantas@deag.ufcg.edu.br

${ }^{3}$ Doutor em Engenharia Agrícola, Prof. da FATEC Cariri, e-mail: carvalho_cmc@yahoo.com.br

${ }^{4}$ Discentes do Curso Superior de Tecnologia em Irrigação e Drenagem, FATEC Cariri, e-mails: leonarialuna@ @otmail.com, simone111oliveira@gmail.com
} 
the interaction of two factors irrigation and fertilization significantly influenced the soluble solids content of the fifth leaf cane sugar variety SP 791011. The sucrose content and purity of the broth increased their values according to water depth. The fiber and the purity of the juice found in the fifth section of the cane sugar in this experiment were higher than those found by other authors who have worked with the same variety and the same place of the experiment, with cuts from previous cane.

Keywords: quality, center pivot, Saccharum officinarum L.

\section{INTRODUÇÃO}

A cana-de-açúcar é uma planta do tipo C4 pertencente ao gênero Saccharum, vindas de regiões temperadas quentes e tropicais da Ásia (BNDS, 2008). Desde então, as indústrias cuja matéria-prima é a cana-de-açúcar se multiplicaram e se modernizaram, levando o País à hegemonia mundial na produção de açúcar e álcool (CHAVES et al., 2003).

Atualmente, o Brasil é o maior produtor mundial de cana-de-açúcar, com produção estimada em mais de 600 milhões de toneladas colhidas em uma área plantada de aproximadamente oito milhões de hectares (CONAB, 2011).

O Brasil é um dos países que asseguram a produção mundial de cana-de-açúcar, sendo seguidos por países como México e EUA. Após a crise do petróleo (1970), a produção de etanol provinda da cana-de-açúcar teve um grande avanço modificando os antigos engenhos da época para a produção de açúcar como para o etanol (MOZAMBANI, 2006).

A Paraíba ocupa a sexta posição no cenário nacional, produzindo 8,9 milhões de toneladas, o que lhe confere uma receita anual de 120 milhões de reais. Com esta cifra, a cana- de-açúcar é o produto, dentro da agropecuária, mais importante do estado (AZEVEDO, 2002).

No entanto, sem o uso da irrigação e da adubação, a produção da cultura pode ser afetada significativamente na quantidade produzida e especialmente na qualidade tecnológica do produto, sendo essas duas práticas juntamente com as condições climáticas do local de grande importância no desenvolvimento da planta e na sua produtividade.

No Brasil as variações climáticas possibilitam duas épocas de colheita anual. Desta forma, apesar da sua grande adaptação às condições climáticas, a cana-de-açúcar apresenta melhores condições quando ocorrer período quente e úmido, com alta radiação solar durante a fase de crescimento, seguido por um período seco, ensolarado e mais frio durante as fases de maturação e colheita (BRUNINI, 2008).

O rendimento na produção de açúcar depende da tonelagem de cana, do teor de açúcar e de sua qualidade (Doorenbos \& Kassan, 1979). O conteúdo de açúcar da cana é de extrema importância, pois é dele que os produtos são obtidos, para a verificação do rendimento da cultura é feita através da determinação dos parâmetros tecnológicos, 
especialmente o ${ }^{\circ}$ BRIX (teor de sólidos solúveis), POL (teor de sacarose), PZA (pureza do caldo), fibra e PCC (percentagem de cana bruta), sendo possível, a partir do conhecimento dessas propriedades, estabelecer critérios para comercialização da cana (Varela, 2002).

Considerando o panorama atual de produtividade dos canaviais na região, diversos fatores podem ser limitantes para o desenvolvimento ideal da cultura, entre esses, a disponibilidade de nutrientes nos solos e a disponibilidade hídrica podem ser apontados como os principais fatores(OLIVEIRA, 2011).

Para Doorenbos \& Kassan (1979), produções de cana de açúcar, em áreas irrigadas em torno de 100 a $150 \mathrm{t} \mathrm{ha}^{-1}$ demandam de 1.500 a $2.000 \mathrm{~mm}$ por ciclo de 365 dias. Pelo fato de que nas áreas canavieiras brasileiras a precipitação total anual é em torno de 1.100 a $1.500 \mathrm{~mm} \mathrm{ano}^{-1}$, segundo Alfonsi et al. (1987) e Carvalho et al. (2009a), torna-se indispensável à irrigação complementar para se obter as produções desejadas.

Silva (2002) afirma que a irrigação, usada como prática suplementar vem sendo cada vez mais utilizada pelos produtores devido a queda na produção de cana-de-açúcar decorrente das baixas precipitações ocorridas no nordeste brasileiro nos últimos anos. Segundo Howell et al. (1990) apud Carvalho et al., (2009b) os parâmetros que ditam a relação entre água e produtividade potencial da cultura são a frequência de aplicação da mesma, a quantidade de lâmina aplicada, a uniformidade e a eficiência de aplicação, juntamente com a precipitação.

Em relação às necessidades nutricionais da cana-de-açúcar, segundo Silva et al. (2009), até o quinto mês de idade a absorção de nutrientes pela cultura é pequena, aumentando intensamente daí em diante, chegando ao nono mês contendo $50 \%$ de potássio, cálcio e magnésio e um pouco mais de $30 \%$ de nitrogênio, fósforo e enxofre do total que absorve durante o ciclo vegetativo; do nono ao décimo segundo mês, a absorção de nitrogênio é ainda mais intensa, acumulando $90 \%$ do total extraído pela planta; o fósforo é absorvido durante todo o ciclo da planta.

Neste contexto o presente trabalho teve como objetivo observar a variação dos parâmetros tecnológicos que afetam diretamente a qualidade da cana-de-açúcar, sob diferentes lâminas de irrigação e níveis adubação de cobertura.

\section{MATERIAL E MÉTODOS}

O experimento foi realizado na Fazenda Capim, da Destilaria Miriri, do Grupo UNIAGRO, situado no município de Capim PB, com a variedade de cana-de-açúcar (Saccharum officinarum L.) SP-791011, cujas coordenadas geográficas são latitude $6^{\circ} 56^{\prime} \mathrm{S}$ e longitude de $35^{\circ} 07^{\prime} \mathrm{W}$, na qual possui uma área irrigada de aproximadamente 600 ha com dois pivôs centrais rebocáveis que se deslocam em seis bases de 50 ha cada uma, Figura 1. A temperatura média anual é de $28^{\circ} \mathrm{C}$, a altitude local é de $100 \mathrm{~m}$, e a precipitação média anual de $1.000 \mathrm{~mm}$, com seis meses secos; o clima é 
quente e úmido, com chuvas de outono a inverno (As' segundo W. Köppen), sendo o bioclima classificado como Mediterrâneo ou Nordestino quente, de seca atenuada (ATLAS GEOGRÁFICO DO ESTADO DA PARAÍBA, 1985). O solo predominante na fazenda é uma associação de Argissolo Vermelho-Amarelo, variação Acinzentado.

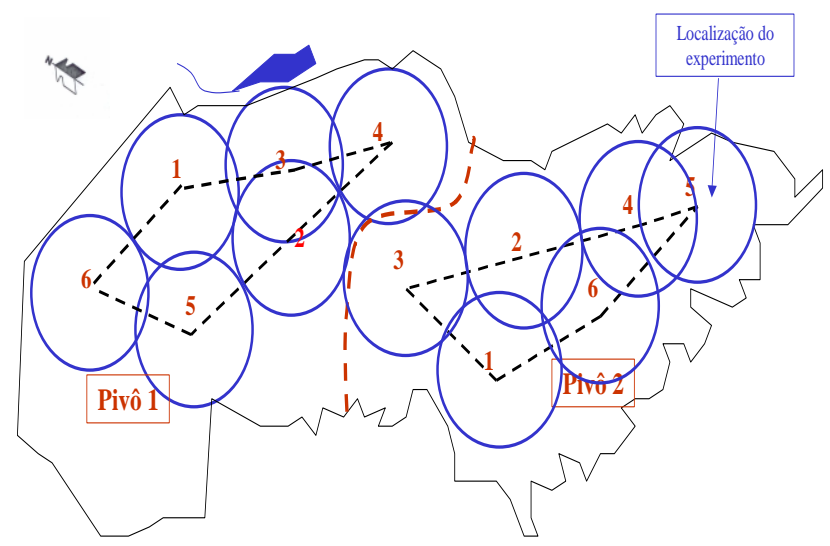

Figura 1. Área irrigada da Fazenda Capim, da Destilaria Miriri, Município de Capim, PB, área de atuação dos pivôs 1 e 2, localização das bases dos pivôs e do experimento.

O experimento foi instalado na base 5 do pivô 2, Figura 1, e os tratamentos em setores do pivô. As parcelas foram constituídas de 5 fileiras espaçadas em $1,20 \mathrm{~m}$, com comprimento de 12,00 m e área total de $72 \mathrm{~m}^{2}$. Portanto a área útil da parcela foi de $36 \mathrm{~m}^{2}$, compreendendo as três fileiras centrais com 10,00 m de comprimento cada uma, sendo a bordadura formada de uma fileira de plantas de cada lado e de 1,00 m em cada extremidade da parcela.

As lâminas foram aplicadas pelo sistema de irrigação por aspersão tipo pivô central rebocável variando-se as velocidades do equipamento por setor, para se aplicar as lâminas dos tratamentos de irrigação.

$\mathrm{O}$ balanço hídrico do experimento foi realizado levando-se em consideração a quantidade de água total (precipitação efetiva mais lâmina líquida da irrigação aplicada), a evapotranspiração real e a capacidade da água aproveitável no solo do experimento, onde o mesmo apresentava alta capacidade de infiltração.

Considerou-se como precipitação efetiva o valor da chuva igual ou menor que a capacidade de água aproveitável do solo e/ou da evapotranspiração real para turno de irrigação de 12 dias. A evapotranspiração real foi calculada pela Eq. 1.

$$
\mathrm{ETr}=0,75 \times \mathrm{Kc} \times \mathrm{EV}
$$

Em que: ETr é a evapotranspiração real, em $\mathrm{mm}$; Kc é o coeficiente de cultivo segundo Doorenbos \& Kassan (1979) adaptado para o período de 14 meses, por DSF (1999); EV é a evaporação do tanque classe $\mathrm{A}$, em $\mathrm{mm}$.

A quantidade de água aplicada em cada irrigação foi igual á evapotranspiração real calculada com base no tanque classe A e na forma apresentada na Equação 1, menos a precipitação efetiva.

Os tratamentos constituíram-se da combinação de dois níveis de adubação de cobertura e quatro lâminas de irrigação. $\mathrm{O}$ arranjo experimental foi um fatorial do tipo $2 \mathrm{x}$ 4 (2 níveis de adubação de cobertura e 4 lâminas de irrigação), num delineamento inteiramente casualizado com três repetições.

Para o fator irrigação, as quantidades 
totais de água compreenderam a precipitação efetiva, mais lâminas de irrigação, com o turno de rega de 12 dias, foram: $W_{0}$ (lâmina $0=$ zero $\mathrm{mm}$ de água de irrigação); $\mathrm{W}_{1}$ (lâmina 1 = 13,8 mm correspondendo a 50\% da lâmina utilizada na Fazenda Capim, (DSF 1999)); $\mathrm{W}_{2}$ (lâmina $2=27,5 \mathrm{~mm}$ equivalente á lâmina utilizada) e $\mathrm{W}_{3}$ (lâmina $3=41,3 \mathrm{~mm}$ referente á lâmina utilizada acrescida de $50 \%)$.

Para o fator adubação, as adubações de cobertura compreenderam os elementos $\mathrm{N}$ e $\mathrm{K}$ em quantidades definidas, tomando-se como base os níveis recomendadas pela equipe de consultores da Destilaria Miriri: $\mathrm{A}_{0}$ (sem aplicação de Nitrogênio $(\mathrm{N})$, Fósforo $\left(\mathrm{P}_{2} \mathrm{O}_{5}\right)$ e Potássio $\left.\left(\mathrm{K}_{2} \mathrm{O}\right)\right)$ e $\mathrm{A}_{1}\left(70 \mathrm{~kg} \mathrm{ha}^{-1}\right.$ de Nitrogênio (N), $25 \mathrm{~kg} \mathrm{ha}^{-1}$ de Fósforo $\left(\mathrm{P}_{2} \mathrm{O}_{5}\right)$ e $110 \mathrm{~kg} \mathrm{ha}^{-1}$ de Potássio $\left.\left(\mathrm{K}_{2} \mathrm{O}\right)\right)$.

A colheita manual foi realizada após a queima da cana. Sendo que em cada parcela útil foi cortada, ao acaso, uma touceira de cana, que foi homogeneizada e moída, retirando-se o caldo da cana que foi analisado no laboratório da destilaria onde foram determinados os seguintes parâmetros tecnológicos da cana-deaçúcar: Teor de sólidos solúveis ou ${ }^{\circ}$ BRIX (\%), Teor de sacarose ou POL (\%), Pureza do caldo ou PZA (\%), Fibra industrial da cana (\%), PCC (percentagem de açúcar bruto) de acordo com Caldas (1998).

\section{Teor de sólidos solúveis ou BRIX (\%)}

O BRIX foi definido a partir do caldo extraído da amostragem de cana de açúcar e para cada amostra, utilizando-se um refratômetro digital, dotado de correção automática de temperatura e ajuste de campo com saída para ajuste magnético. $\mathrm{O}$ funcionamento deste aparelho se fundamenta na relação entre incidência e refração. Os resultados finais dos ensaios foram corrigidos para a temperatura de $20^{\circ} \mathrm{C}$. O índice de refração que corresponde ao índice de sólidos solúveis ou Brix é obtido pela expressão:

$$
\mathrm{I}_{\mathrm{r}}=\frac{\operatorname{sen}(\mathrm{i})}{\operatorname{sen}(\mathrm{r})}
$$

Em que $I_{r}$ é o Brix ou teor de sólidos solúveis; Sen(i) é o seno do ângulo de incidência; Sen(r) é o seno do ângulo de refração.

\section{Teor de sacarose ou POL (\%)}

$O$ teor de sacarose foi determinado utilizando-se um aparelho denominado sacarímetro automático do tipo $\mathrm{ACATEC}^{\mathrm{R}}$, modelo DAS 2500. O funcionamento dos sacarímetros é baseado em princípios físicos, tomando-se como base as propriedades da luz e sua natureza ondulatória definindo assim, a concentração de açúcares opticamente ativos, do tipo sacarose.

A partir da Lei de Biot (CALDAS,1998) e da equação que exprime esta Lei é que se determina o teor de sacarose na cana-deaçúcar.

$$
C=\frac{100 * \alpha}{I^{*} \alpha^{\top *} Y}
$$

Em que $C$ é a concentração de açúcar; $\alpha$ é o ângulo de rotação do plano de vibração da luz polarizada; 1 é o comprimento da coluna iluminada de líquido; $\alpha^{\mathrm{T}} * \gamma$ é a rotação 
específica.

O resultado obtido diretamente no sacarímetro não é ainda o definitivo, sendo necessária a correção da leitura para ajustá-lo à temperatura do ambiente, utilizando-se a seguinte equação para a correção:

$$
\mathrm{L}_{\text {corr }}=\mathrm{L}^{*}[1+0,000255(\mathrm{~T}-20)]
$$

Em que L é a leitura no sacarímetro; T é a temperatura ambiente; $\mathrm{L}_{\text {corr }}$ é a leitura corrigida correspondente ao $\operatorname{POL}(\%)$.

\section{Pureza do caldo (PZA)}

É determinada empiricamente, calculada a partir da percentagem de sólidos solúveis totais no caldo extraído, após a determinação do POL e do BRIX. De acordo com Caldas (1998) e CRSPCTS/PB (1997), a Pureza é determinada pela expressão:

$$
\mathrm{PZA}=\frac{\mathrm{POL}_{\% \text { caldo }}}{\mathrm{BRIX} \% \text { caldo }}
$$

Em que: POL é o teor de sacarose; BRIX é o teor de sólidos solúveis.

\section{Fibra industrial da cana $(\%)$}

Para determinar o percentual de fibra industrial na cana procede-se, através de um método comparativo, à verificação da correlação existente entre o resíduo fibroso e a fibra industrial. Esta determinação é feita experimentalmente, pela seguinte equação (CRSPCTS/PB,1997):

$$
\% \mathrm{FI}_{\text {cana }}=\frac{(100 * \mathrm{PS}) *\left(\mathrm{PU}{ }^{*} \mathrm{~b}\right)}{5^{*}(100-\mathrm{b})}
$$

Em que PS é o peso do bolo seco em estufa a $105^{\circ} \mathrm{C}$; PU é o peso do bolo úmido (resíduo fibroso); b é o BRIX do caldo extraído.

\section{PCC (percentagem de açúcar bruto)}

O PCC é um índice que fornece a ideia do valor da tonelada da cana, que varia diretamente proporcional a este índice, isto é, para valores elevados de PCC ter-se-ão os preços da cana crescendo no mercado e viceversa. O PCC é determinado pela equação:

$$
P C C=L_{c o r r} *(1-0,01 * F I) * c
$$

Em que: $\mathrm{L}_{\text {corr }}$ é o POL do caldo extraído (\%); FI é a fibra industrial em \% da cana; c é fator de transformação da POL do caldo extraído em POL do caldo absoluto, sendo igual a 0,955.

As variáveis avaliadas foram submetidas à análise de variância (Anova). Posteriormente, quando significativas pelo teste $\mathrm{F}$, as variáveis dos parâmetros tecnológicos, aos efeitos das diferentes lâminas de irrigação e níveis de adubação de cobertura foram submetidos à análise de regressão.

$\mathrm{Na}$ análise de regressão, as equações que melhor se ajustaram aos dados foram selecionadas com base na significância dos coeficientes de regressão a $1 \%(* *)$ e $5 \%(*)$ de probabilidade pelo teste $\mathrm{F}$ e no maior coeficiente de determinação $\left(\mathrm{R}^{2}\right)$. Os estudos da análise de variância e análise de regressão foram realizados com o auxílio de planilhas eletrônicas do Excel e utilizando o software “ASSISTAT” Versão Beta 6.2 2006. 


\section{RESULTADOS E DISCUSSÃO}

\section{Lâminas de irrigação}

As quantidades de água aplicadas por intermédio da irrigação durante todo $\mathrm{o}$ experimento foram: $\mathrm{W}_{0}(0 \mathrm{~mm})=0 \mathrm{~mm}, \mathrm{~W}_{1}$ $(13,8 \mathrm{~mm})=193 \mathrm{~mm}, \mathrm{~W}_{2}(27,5 \mathrm{~mm})=385 \mathrm{~mm}$ e $\mathrm{W}_{3}(41,3)=578 \mathrm{~mm}$. A precipitação efetiva acumulada no período foi $671 \mathrm{~mm}$, assim as quantidades totais de água aplicadas para todo o ciclo foram: $\mathrm{W}_{0}+\mathrm{P}_{\mathrm{ef}}=671 \mathrm{~mm}, \mathrm{~W}_{1}+\mathrm{P}_{\mathrm{ef}}=$ $864 \mathrm{~mm}, \mathrm{~W}_{2}+\mathrm{P}_{\mathrm{ef}}=1056 \mathrm{~mm} \mathrm{e} \mathrm{W}_{3}+\mathrm{P}_{\mathrm{ef}}=1249$ $\mathrm{mm}$, valores inferiores aos recomendados por Doorenbos \& Kassan (1979), para o período de 365 dias, que varia de 1500 a $2000 \mathrm{~mm}$.

Na Figura 2 encontra-se apresentado a necessidade hídrica da cultura, onde observa-se que houve déficit na planta em quase todos os tratamentos e em quase todos os meses.

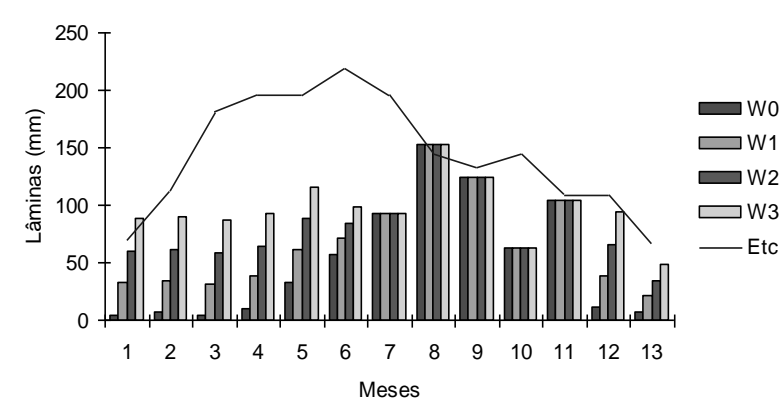

Figura 2. Necessidade hídrica da cana-de-açúcar e lâminas de água aplicadas nos diferentes tratamentos ao longo do ciclo, $5^{\text {a }}$ folha, variedade SP 791011.

\section{Parâmetros tecnológicos}

Nas Tabelas 1, 2 e 3 são apresentados os resultados da análise de variância e a comparação das médias dos parâmetros tecnológicos ( ${ }^{\circ} \mathrm{BRIX}$ - Teor de sólidos solúveis
(\%), POL - Teor de sacarose (\%), PZA - Pureza do caldo (\%), Fibra industrial da cana (\%), PCC - percentagem de açúcar bruto (\%), da cana-de-açúcar e valores destes parâmetros obtidos por vários autores.

Tabela 1. Análise de variância dos parâmetros tecnológicos.

\begin{tabular}{|c|c|c|c|c|c|c|}
\hline \multirow{2}{*}{$\begin{array}{l}\text { Fonte de } \\
\text { Variação }\end{array}$} & \multicolumn{6}{|c|}{ Teste F } \\
\hline & GL & ${ }^{\circ}$ BRIX & POL & PZA & FIBRA & PCC \\
\hline Adubação (F 1) & 1 & $0,1175^{\mathrm{ns}}$ & $0,2976^{\mathrm{ns}}$ & $0,1560^{\mathrm{ns}}$ & $0,0230^{*}$ & $0,2095^{\mathrm{ns}}$ \\
\hline Irrigação (F 2) & 3 & $0,0742^{\mathrm{ns}}$ & $0,0442 *$ & $0,0018 * *$ & $0,6876^{\mathrm{ns}}$ & $0,0536^{\mathrm{ns}}$ \\
\hline Interação (F 1 x F 2) & 3 & $0,0329 *$ & $0,5000^{\mathrm{ns}}$ & $0,6387^{\text {ns }}$ & $0,6125^{\text {ns }}$ & $0,4963^{\text {ns }}$ \\
\hline QM (resíduo) & 21 & 0,29316 & 0,63101 & 3,78756 & 1,07762 & 0,524276 \\
\hline Média Geral & & 21,03 & 18,64 & 89,31 & 16,65 & 14,60 \\
\hline $\mathrm{CV}$ & & 2,57 & 4,25 & 2,18 & 6,23 & 4,96 \\
\hline
\end{tabular}

${ }^{\circ}$ BRIX - teor de sólidos solúveis; POL - Teor de sacarose; PZA - Pureza do caldo; FIBRA - Fibra insdústrial da cana; PCC - Percentagem de açúcar bruto; ** - significativo a nível de $1 \%$ de probabilidade; * significativo a nível de $5 \%$ de probabilidade; ${ }^{\text {ns }}$ - não significativo; QM - Quadrado Médio; CV - Coeficiente de Variação.

Tabela 2 - Comparação das médias dos parâmetros tecnológicos.

\begin{tabular}{cccccc}
\hline & ${ }^{\circ}$ BRIX & POL & PZA & FIBRA & PCC \\
\hline $\mathrm{W}_{0}$ & $20,62500 \mathrm{a}$ & $18,12500 \mathrm{~b}$ & $87,16250 \mathrm{c}$ & $16,62500 \mathrm{a}$ & $14,09525 \mathrm{a}$ \\
& & & & & \\
$\mathrm{W}_{1}$ & $21,00000 \mathrm{a}$ & $18,42500 \mathrm{~b}$ & $88,62500 \mathrm{bc}$ & $17,00000 \mathrm{a}$ & $14,37500 \mathrm{a}$ \\
& & & & & \\
$\mathrm{W}_{2}$ & $21,37500 \mathrm{a}$ & $19,03750 \mathrm{a}$ & $90,00000 \mathrm{ab}$ & $16,60000 \mathrm{a}$ & $15,03762 \mathrm{a}$ \\
& & & & & \\
$\mathrm{W}_{3}$ & $21,12500 \mathrm{a}$ & $19,18750 \mathrm{a}$ & $91,43750 \mathrm{a}$ & $16,37500 \mathrm{a}$ & $14,90500 \mathrm{a}$
\end{tabular}

${ }^{\circ}$ BRIX - teor de sólidos solúveis; POL - Teor de sacarose; PZA - Pureza do caldo; FIBRA - Fibra industrial da cana; PCC - Percentagem de açúcar bruto. 
Tabela 3. Valores médios dos parâmetros tecnológicos da cana obtidos pelos seguintes autores.

\begin{tabular}{|c|c|c|c|c|c|}
\hline \multirow{2}{*}{ 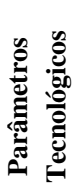 } & \multicolumn{5}{|c|}{ Autores (Ano) } \\
\hline & $\begin{array}{c}\text { Azevedo }^{1} \\
\text { (2002) }\end{array}$ & $\begin{array}{c}\text { Moura }^{2} \\
(2003)\end{array}$ & $\begin{array}{l}\text { Silva } \\
(2003)\end{array}$ & $\begin{array}{c}\text { Carvalho }^{4} \\
(2003)\end{array}$ & $\begin{array}{c}\text { Dados deste } \\
\text { experimento }\end{array}$ \\
\hline${ }^{\circ} \mathrm{BRIX}$ & $\begin{array}{c}22,11 \\
(1.043)^{*}\end{array}$ & $\begin{array}{c}19,15 \\
-\end{array}$ & $\begin{array}{c}20,36 \\
(955,1)^{*}\end{array}$ & $\begin{array}{c}20,56 \\
(1.065)^{*}\end{array}$ & $\begin{array}{c}21,03 \\
(1.168)^{*}\end{array}$ \\
\hline POL & $\begin{array}{c}19,45 \\
(1.043)^{*}\end{array}$ & $\begin{array}{c}16,79 \\
(955,1)^{*}\end{array}$ & $\begin{array}{c}17,90 \\
(955,1)^{*}\end{array}$ & $\begin{array}{c}18,15 \\
(1.065)^{*}\end{array}$ & $\begin{array}{c}18,64 \\
(1.168)^{*}\end{array}$ \\
\hline PZA & $\begin{array}{c}87,32 \\
(1.043)^{*}\end{array}$ & $\begin{array}{c}87,86 \\
(955,1)^{*}\end{array}$ & $\begin{array}{c}87,90 \\
(955,1)^{*}\end{array}$ & $\begin{array}{c}88,30 \\
-\end{array}$ & $\begin{array}{c}89,31 \\
(1.168)^{*}\end{array}$ \\
\hline FIBRA & $\begin{array}{c}14,51 \\
(1.043)^{*}\end{array}$ & $\begin{array}{c}13,88 \\
(955,1)^{*}\end{array}$ & $\begin{array}{c}13,89 \\
(955,1)^{*}\end{array}$ & $\begin{array}{c}13,91 \\
(1.065)^{*}\end{array}$ & $\begin{array}{c}16,65 \\
(1.168)^{*}\end{array}$ \\
\hline PCC & $\begin{array}{c}16,18 \\
(1.043)^{*}\end{array}$ & $\begin{array}{c}13,72 \\
(955,1)^{*}\end{array}$ & $\begin{array}{c}14,64 \\
(955,1)^{*}\end{array}$ & $\begin{array}{c}14,84 \\
-\end{array}$ & $\begin{array}{c}14,60 \\
(1.168)^{*}\end{array}$ \\
\hline
\end{tabular}

${ }^{1}$ Azevedo (2002) trabalhando com cana planta (SP 791011) na mesma parcela do experimento; ${ }^{2}$ Moura (2003) trabalhando com a segunda folha de cana (SP 791011) na mesma parcela do experimento; ${ }^{3}$ Silva (2003) trabalhando com a terceira folha de cana (SP 791011) na mesma parcela do experimento; ${ }^{4}$ Carvalho (2003) trabalhando com a terceira folha de cana (SP 791011) na mesma parcela do experimento; ${ }^{5}$ Valores médios dos parâmetros tecnológicos obtidos neste trabalho. ( )* Total de água aplicado em mm.

$\mathrm{Na}$ analise de variância dos parâmetros tecnológicos apresentados na Tabela 1, observou-se que, para o fator irrigação houve diferença significativa no POL a $5 \%$ de probabilidade e para o PZA a $1 \%$ de probabilidade. Já na adubação houve diferença significativa para a FIBRA a $1 \%$ de probabilidade, e quanto à interação só houve diferença significativa no ${ }^{\circ}$ BRIX a $5 \%$ de probabilidade.

\section{Sólidos solúveis $\left({ }^{\circ}\right.$ BRIX)}

$\mathrm{Na}$ Tabela 1, observa-se que quando se aplicou o teste $\mathrm{F}$, o mesmo foi significativo a
5\% de probabilidade na interação dos dois fatores e não foi significativo nas diferentes lâminas de irrigação e nos níveis de adubação. O coeficiente de variação foi de 2,57\%, classificado por Gomes (1990) como baixo, indicando que o delineamento estatístico utilizado exerceu bom controle sobre as variações do meio.

$\mathrm{Na}$ aplicação do teste de Tukey ao nível de $5 \%$ de probabilidade, observou-se que a média da interação difere estatisticamente entre si, onde se verificou pela Figura 3, que o ${ }^{\circ}$ BRIX alcançou o valor máximo de 21,75 com a lâmina $\mathrm{W}_{3}$ e com adubação $\mathrm{A}_{1}$ e o seu menor valor é de 20,50 com a lâmina $W_{0}$ e $A_{0}$ sem adubação (Figura 3).

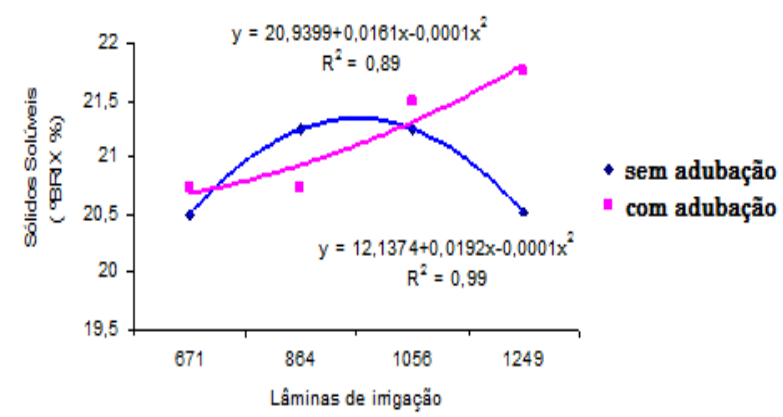

Figura 3. Sólidos Solúveis ( ${ }^{\circ}$ BRIX) em relação à lâmina de irrigação e ao nível de adubação de cobertura, de cana-de-açúcar, $5^{\text {a }}$ folha, Variedade SP79-1011.

De acordo com a Tabela 3, constata-se que o valor médio do ${ }^{\circ}$ BRIX encontrado é inferior á média apontada por Azevedo (2002) trabalhando com a cana planta, porém superior aos valores encontrados por Moura (2003), Silva (2003) e Carvalho (2003) trabalhando com a segunda e terceira folha de cana-deaçúcar, respectivamente. 


\section{Teor de sacarose (POL)}

A análise de variância apresentada na Tabela 1, pelo teste de Tukey apenas o fator irrigação foi significativo a $5 \%$ de probabilidade, e quanto à interação dos dois fatores não foi significativa, o coeficiente de variação foi igual a $4,25 \%$ e a media geral foi de 18,64 .

O menor valor do teor de sacarose obtido no experimento foi de $18,04 \%$ no tratamento $\mathrm{W}_{0} \mathrm{~N}_{0}$, e o maior valor obtido foi de $19,59 \%$ no tratamento $\mathrm{W}_{3} \mathrm{~A}_{1}$.

Na Tabela 3, observa-se que o valor médio do POL encontrado é inferior á média apontada por Azevedo (2002) trabalhando com a cana planta, porém superior aos valores encontrados por Moura (2003), Silva (2003) e Carvalho (2003) trabalhando com a segunda e terceira folha de cana-de-açúcar, respectivamente.

\section{Pureza do caldo (PZA)}

Pelo o teste de Tukey o fator irrigação foi significativo a $1 \%$, enquanto que a adubação não foi significativa, e que a interação dos dois fatores não houve diferença significativa. $O$ experimento mostrou um coeficiente de variação igual a 2,18\%, classificado como baixo, por Gomes (1990) indicando que o delineamento estatístico utilizado exerceu bom comtrole sobre as variações do meio, e sua media geral foi de $89,31 \%$.

Observando a Tabela 2, verificaram-se pelo teste de Tukey ao nível de $5 \%$ de probabilidade, que a lâmina de irrigação $\mathrm{W}_{3}$, foi superior as lâminas $\mathrm{W}_{0} \mathrm{e} \mathrm{W}_{1}$. O menor valor de PZA (pureza do caldo em \%) obtido no experimento foi de $86,47 \%$ no tratamento $\mathrm{W}_{0} \mathrm{~A}_{1}$, e o máximo de $92,47 \%$ no tratamento $\mathrm{W}_{3} \mathrm{~A}_{0}$.

Pela Tabela 3, nota-se que o valor médio de PZA é superior a todos os valores médios encontrados, inclusive ao valor obtido por Azevedo (2002) trabalhando com cana planta, cultivar SP 791011, na mesma parcela deste experimento.

\section{Fibra}

$\mathrm{Na}$ análise de variância, apresentada na Tabela 1, pelo o teste de Tukey apenas o fator adubação foi significativo a $5 \%$ de probabilidade, e a interação dos dois fatores não foi significativa, o coeficiente de variação foi igual a $6,23 \%$ e a media geral foi de 16,65 .

Com relação ao fator adubação, verificou-se através do teste de Tukey, que o nível $\mathrm{A}_{1}$, superou significativamente o nível $\mathrm{A}_{0}$ ao nível de $5 \%$ de probabilidade. Na Figura 4, observa-se que o nível $\mathrm{A}_{1}$ atingiu a fibra industrial de $17,10 \%$, sendo superior ao $\mathrm{A}_{0}$ que atingiu o valor de $16,20 \%$.

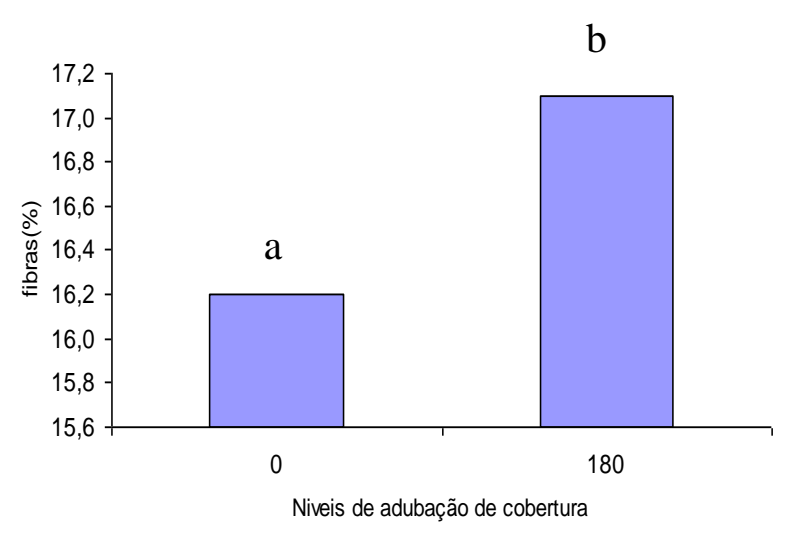

Figura 4. Comparação entre as médias da fibra industrial (\%), com relação ao fator adubação, da cana-de-açúcar, variedade SP 79-1011. 
De acordo com a Tabela 3, nota-se que o valor médio de fibra industrial é superior a todos os valores médios encontrados, inclusive ao valor obtido por Azevedo (2002) trabalhando com cana planta, cultivar SP 791011, na mesma parcela deste experimento.

Segundo Castro \& Kluge (2001), o teor de fibra no colmo pode ser considerado um fator antieconômico no processo industrial, razão pela qual geralmente a moagem da canade-açúcar está regulada para canas com 12,5\% de fibra. A cada acréscimo de 0,5 de fibra, ocorre redução de 10 a $20 \%$ no rendimento da moagem e cada $1 \%$ de acréscimo de fibra pode reduzir em torno de $1,85 \mathrm{~kg}$ de açúcar por tonelada.

\section{Percentagem de açúcar bruto (PCC)}

Pela análise de variância indicada na Tabela 1, oexperimento apresentou coeficiente de variação igual a $4,96 \%$, e a média geral foi de $14,60 \%$. O teste $\mathrm{F}$ demonstrou que não houve significância entre os fatores analisados, isto é, as variações na percentagem bruta de açúcar (PCC) foram devidas ao acaso. O menor valor da percentagem bruta de açúcar (PCC) obtido no trabalho foi de $14,02 \%$ no tratamento $\mathrm{W}_{0} \mathrm{~A}_{0}$ e o máximo obtido foi de $15,48 \%$, no tratamento $\mathrm{W}_{1} \mathrm{~A}_{1}$.

Silva (2002) avaliando a resposta da cana-de-açúcar sob diferentes níveis de adubação nos tabuleiros costeiros da Paraíba, cultivar SP 716949, encontrou 14,49\% para valor médio de PCC e Andrade et al. (2000), avaliando os efeitos de fontes (aquamônia e uréia) e dosagens de nitrogênio em soqueira de cana-de-açúcar, cultivar SP 79-2233, encontraram para PCC com aquamônia 17,12\% e, com uréia, $17,13 \%$.

\section{CONCLUSÕES}

A variável Fibra foi a única variável afetada significamente pela aplicação dos níveis de adubação de cobertura alcançando o maior valor quando submetido a adubação correspondente a70 $\mathrm{kg} \mathrm{ha}^{-1}$ de Nitrogênio $(\mathrm{N})$, $25 \mathrm{~kg} \mathrm{ha}^{-1}$ de Fósforo $\left(\mathrm{P}_{2} \mathrm{O}_{5}\right)$ e $110 \mathrm{~kg} \mathrm{ha}^{-1}$ de Potássio $\left(\mathrm{K}_{2} \mathrm{O}\right)$, as variáveis POL e PZA foram crescentes com a aplicação das lâminas de irrigação alcançando os maiores valores quando aplicada a lâmina total de 1.249 mm e o ${ }^{\circ}$ BRIX foi influenciada pela interação dos dois fatores alcançando o maior valor quando aplicada a maior lâmina total de $1.249 \mathrm{~mm} \mathrm{e}$ com adubação de cobertura de $70 \mathrm{~kg} \mathrm{ha}^{-1}$ de Nitrogênio (N), $25 \mathrm{~kg} \mathrm{ha}^{-1}$ de Fósforo $\left(\mathrm{P}_{2} \mathrm{O}_{5}\right)$ e $110 \mathrm{~kg} \mathrm{ha}^{-1}$ de Potássio $\left(\mathrm{K}_{2} \mathrm{O}\right)$.

\section{AGRADECIMENTOS}

Os autores agradecem a Usina Miriri pertencente ao Grupo Uniagro por todo o apoio na realização do experimento. 


\section{REFERÊNCIAS BIBLIOGRÁFICAS}

ALFONSI, R. R.; PEDRO JÚNIOR, M. J.; BRUNINI, O.; BARBIERI, V. Condições climáticas para a cana-de-açúcar. In: Paranhos, S. B. coord. Cana-de-açúcar: cultivo e utilização. Campinas: fundação Cargill, 1987. v.1, cap.1, p.42-55.

ANDRADE, L. A.; BOCARDO, M. R.; CORREA, J. B. D.; CARVALHO, G. J. de. Efeito do nitrogênio, aplicado nas formas fluída ou sólida, em soqueira de cana-de-açúcar. Ciência Agropecuária, v.24, n.2, p.516-520, 2000.

ATLAS GEOGRÁFICO DO ESTADO DA PARAÍBA. João Pessoa: Secretaria de Educação/UFPB, 1985. 99 p.

AZEVEDO, H. M. de. Resposta da cana-deaçúcar a níveis de irrigação e de adubação de cobertura nos tabuleiros costeiros da Paraíba. 2002. 87 p. Doutorado (Engenharia Agrícola) - Universidade Federal de Campina Grande, Campina Grande.

BNDS. Bioetanol de cana-de-açúcar: energia para o desenvolvimento sustentável. Organização BNDS/CGEE. Rio de Janeiro: BNDS, 2008, 316p. Disponível em: http://www.bioetanoldecana.org/pt/download/b ioetanol.pdf. Acesso em: 18 fev. 2013.

BRUNINI, O. Ambientes climáticos e exploração agrícola da cana-de-açúcar. In: DINARDO-MIRANDA, L. L.; VASCONCELOS, A.C M. de; ANDRADE LANDELL, M. G. DE. Cana-de-açúcar. Campinas: Instituto Agronômico, 2008. p. 205218.

CALDAS, C. Manual de análises selecionadas para indústrias sucroalcooleiras. Maceió: Sindicato da Indústria e do Álcool do Estado de Alagoas, 1998. 424p.
CARVALHO, C. M. de. Rendimento da cana, terceira folha, sob diferentes níveis de irrigação nos tabuleiros costeiros da Paraíba. 2003. 80 p. Mestrado (Engenharia Agrícola) - Universidade Federal de Campina Grande, Campina Grande.

CARVALHO, C. M. de; AZEVEDO, H. M. de; DANTAS NETO, J.; FARIAS, C. H. de A.; SILVA, C. T. S. da; GOMES FILHO, R. R. Rendimento de açúcar e álcool da cana-deaçúcar submetida a diferentes níveis de irrigação. Revista Brasileira de Ciências Agrárias. Recife, v.4, n.1, p.72-77, 2009b.

CARVALHO, C. M. de; AZEVEDO, H. M. de; DANTAS NETO, J.; SILVA, C. T. S. da; GOMES FILHO, R. R.; VALNIR JÚNIOR, M. Influência de diferentes níveis de irrigação sobre os parâmetros organográficos da cana-deaçúcar. Revista Brasileira de Ciências Agrárias. Recife, v.4, n.2, p.173-178, 2009a.

CASTRO, P.R.C.; KLUGE, R.A. Ecofisiologia de culturas extrativas: cana-de-açúcar; seringueira; coqueiro; dendezeiro e oliveira. Cosmópolis: Stoller do Brasil Ltda, 2001. 138p.: il.

CHAVES, J. B. P.; SILVA, C. A. B. da; SILVA, F. C. da; CESAR, M. A. A. Produção, Qualidade e Mercado de Açúcar Mascavo, Melado e Rapadura, no Brasil. In: Silva, F. C. da; Cesar, M. A. A.; Silva, C. A. B. da. (ed.). Pequenas indústrias rurais de cana-de-açúcar: melado, rapadura e açúcar mascavo. Brasília: Embrapa Informação Tecnológica, 2003. Cap. 1, p. 11-20.

CONAB - COMPANHIA NACIONAL DE ABASTECIMENTO. Acompanhamento da safra brasileira: cana-de-açúcar safra 2010/2011. Terceiro Levantamento, janeiro/2011. Brasília, Conab, 2011.

CRSPCTS/PB, Instituto do Açúcar e do Álcool. Manual Técnico de Operação. Julho 1997. 
DOORENBOS, J.; KASSAN, A. H. Yield response to water. $\mathrm{FAO}$ - Rome. (Copyright (C) $1979 b, 306 p$.

DSF. Projeto de Irrigação: pivô central rebocável. Rio Tinto- PB: União Agrícola Ltda, 1999. 73p.

GOMES, F. P. Curso de estatística experimental. 13.ed. Piracicaba: Nobel, 1990. 486p.

LAVANHOLI, M. G. D. P. Qualidade da canade-açúcar como matéria-prima para a produção de açúcar e álcool. In: DINARDOMIRANDA, L. L.; VASCONCELOS, A.C M. de; ANDRADE LANDELL, M. G. DE. Canade-açúcar. Campinas: Instituto Agronômico, 2008. p. 697-722.

MOURA, M. V. P. da S. Resposta da cana-deaçúcar irrigada, segunda folha, á níveis adubação nos tabuleiros costeiros da Paraíba. 2003. 60 p. Mestrado (Engenharia Agrícola) - Universidade Federal de Campina Grande, Campina Grande.

MOZANBALI, J. R. História e morfologia da cana-de-açúcar: atualização em produção de cana-de-açúcar. Piracicaba: CP2, 2006.

OLIVEIRA, E .C .A. Balanço nutricional da cana-de-açúcar relacionada à adubação nitrogenada. 2011. 213 p. Tese(Doutorado em Solos e Nutrição de Plantas) - Escola Superior de Agricultura "Luiz de Queiroz", Universidade de São Paulo,Piracicaba.

SILVA, A. B. da. Resposta da cana-deaçúcar irrigada sob diferentes níveis de adubação. 2002. 61 p. Mestrado (Engenharia Agrícola) - Universidade Federal da Paraíba, Campina Grande.

SILVA, C. T. S. da. Efeito de diferentes níveis de adubação sobre a produção da terceira folha de cana irrigada nos tabuleiros costeiros da Paraíba. 2003. 81 p. Mestrado (Engenharia Agrícola) - Universidade Federal de Campina Grande, Campina Grande.

SILVA, C. T. S. da; AZEVEDO, H. M. de; AZEVEDO, C. A. V. de; DANTAS NETO, J.; CARVALHO, C. M. de; GOMES FILHO, R. R. Crescimento da cana-de-açúcar com e sem irrigação complementar sob diferentes níveis de adubação de cobertura nitrogenada e potássica. Revista Brasileira de Agricultura Irrigada. Fortaleza, v.3, n.1, p.3-12, 2009.

VARELA, A. C. G. Análise do Comportamento Morfofisiológico da Canade-açúcar Irrigada (Variedades SP 791011 e SP 716949), nos Tabuleiros Costeiros Paraibanos. Campina Grande: UFCG, 2002. 89p. Dissertação de Mestrado. 